\title{
Effects of response-independent stimulus delivery and functional communication training
}

Shannon S. Haag

West Virginia University

Follow this and additional works at: https://researchrepository.wvu.edu/etd

\section{Recommended Citation}

Haag, Shannon S., "Effects of response-independent stimulus delivery and functional communication training" (2002). Graduate Theses, Dissertations, and Problem Reports. 885.

https://researchrepository.wvu.edu/etd/885

This Thesis is protected by copyright and/or related rights. It has been brought to you by the The Research Repository @ WVU with permission from the rights-holder(s). You are free to use this Thesis in any way that is permitted by the copyright and related rights legislation that applies to your use. For other uses you must obtain permission from the rights-holder(s) directly, unless additional rights are indicated by a Creative Commons license in the record and/ or on the work itself. This Thesis has been accepted for inclusion in WVU Graduate Theses, Dissertations, and Problem Reports collection by an authorized administrator of The Research Repository @ WVU. For more information, please contact researchrepository@mail.wvu.edu. 


\title{
Effects of Response-Independent Stimulus Delivery and Functional Communication Training
}

\section{Shannon S. Haag}

\author{
Thesis submitted to the College of Arts and Sciences \\ at West Virginia University \\ in partial fulfillment of the requirements \\ for the degree of
}

\author{
Master of Arts \\ in \\ Psychology
}

Cynthia M. Anderson, Ph.D., Committee Chair

Kennon A. Lattal, Ph.D.

Tracy L. Morris, Ph.D.

Department of Psychology

Morgantown, West Virginia

2002

Keywords: noncontingent reinforcement, functional communication training, extinction, problem behavior, manding, developmental disabilities 


\author{
Abstract \\ Effects of Response-Independent Stimulus Delivery \\ and Functional Communication Training \\ Shannon S. Haag
}

Two individuals with developmental delays with a history of problem behavior participated in this study. Its purpose was to examine the efficacy of combining two treatments demonstrated to reduce problem behavior: response-independent stimulus delivery and differential reinforcement of an alternative behavior. This study examined whether the response-independent delivery of an alternative preferred stimulus and differential reinforcement of manding resulted in increases in manding and suppression of problem behavior prior to and during the fading of the schedule of response-independent stimulus delivery. The study also examined the necessity of extinction to obtain suppression of problem behavior. The response-independent delivery of an alternative preferred stimulus and the implementation of functional communication training resulting in access to the maintaining reinforcer increased manding and decreased problem behavior. Results also suggest tentatively that extinction may be necessary to maintain response suppression during fading of the response-independent stimulus delivery schedule. 


\section{Acknowledgments}

I would like to thank my committee: Cindy Anderson, Andy Lattal, and Tracy Morris. Each has contributed a unique perspective to this thesis, be it applied, basic, or clinical, and each is appreciated. I particularly would like to offer gratitude to Cindy, who has been available on a moment's notice to help with participants and to listen and offer advice. I appreciate her support and for allowing me a balance of assistance and independence as I learned more about applied research.

I would also like to extend deep gratitude to those who assisted in data collection and analysis; specifically Heather Barclay, Carie English, Lindsay Hauer, Raina Hosey, Meghan Moore, Cooper Mackey, and Lisa Ware. I also thank Christine Kim for her encouragement in graduate school that has helped me tremendously, as well as her advice on various aspects of this experiment. I would like to thank Adam Doughty for his thoughtful contributions to an earlier version of this thesis, as well as his patience, understanding, and friendship throughout the course of this project and graduate school. He has helped me to become a better student and a better person and I am very grateful for that.

Finally, I would like to thank my family — my parents, Michael and Debra, and my sister, Kelly, without whose help, love, and support this opportunity would not be possible. 
List of Tables

Page

Table 1. Therapist Responses during Functional Analysis.................................. 12

Table 2. Mean Agreement Scores for Child and Adult Responses............................13

Table 3. Schedule of Stimulus Delivery for Logan..................................... 18

Table 4. Schedule of Stimulus Delivery for Nicholas.................................... 19 


\section{List of Figures}

Figure 1. Rates of Problem Behavior during Functional Analysis for Logan................21

Figure 2. Rates of Problem Behavior during Alternative-Stimulus Testing Condition for

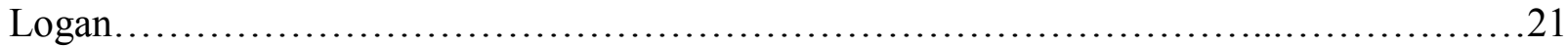

Figure 3. Rates of Problem Behavior and Manding during Evaluation of Response-Independent

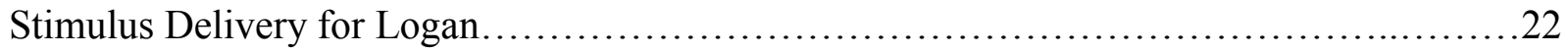

Figure 4. Rates of Problem Behavior during Functional Analysis for Nicholas...............25

Figure 5. Rates of Problem Behavior during Alternative-Stimulus Testing Condition for

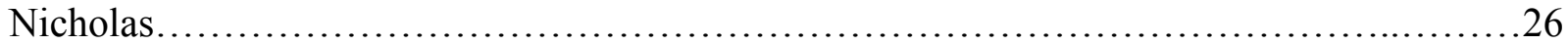

Figure 6. Rates of Problem Behavior and Manding during Evaluation of Response-Independent

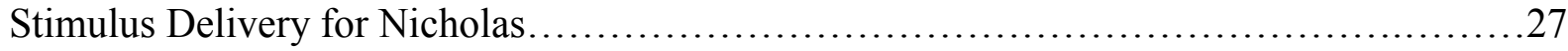


Effects of Response-Independent Stimulus Delivery and Functional Communication Training

Table of Contents

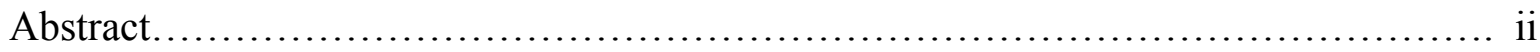

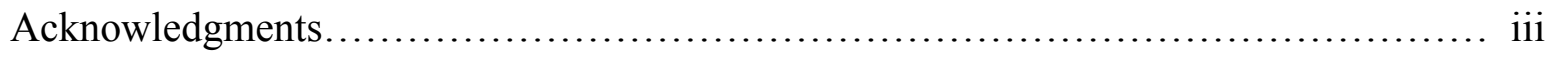

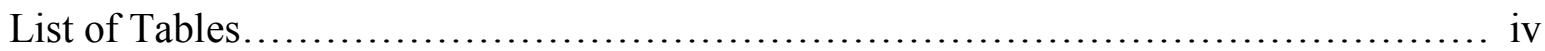

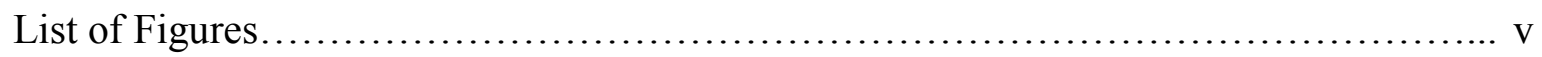

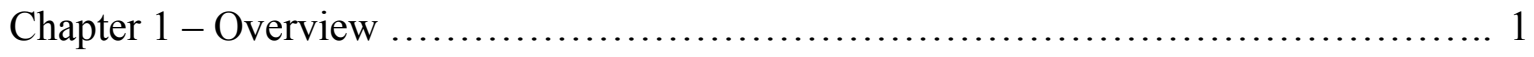

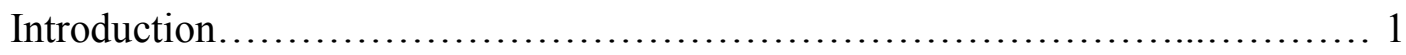

Literature Review......................................................... 2

Functional Communication Training...................................

Response-Independent Stimulus Delivery............................... 3

Basic research........................................... 4

RISD of the maintaining reinforcer......................... 4

RISD of an alternative stimulus............................ 5

RISD compared to differential reinforcement.................7

RISD with FCT ........................................... 8

Statement of the Problem.................................................. 9

Chapter 2 - Experimental Method and Results ….................................. 9

Method............................................................................ 9

Participants and Setting ............................................ 9

Experimental Design.......................................... 10

Response Definitions, Data Collection, and Interobserver Agreement...... 10 
Procedure........................................................ 14

Phase 1: Functional analysis................................ 14

Phase 2: Preference assessment............................ 15

Phase 3: Evaluation of RISD .............................. 15

Testing the alternative stimulus............................. 15

Functional communication training..................... 16

RISD, without extinction, with differential reinforcement of manding $\ldots \ldots \ldots \ldots \ldots \ldots \ldots \ldots \ldots \ldots \ldots \ldots \ldots \ldots \ldots \ldots \ldots \ldots \ldots, 16$

RISD, with extinction, with differential reinforcement of manding

Results and Discussion.............................................. 17

Logan..................................................... 20

Functional analysis....................................... 20

Preference assessment...................................... 20

Testing the alternative stimulus........................... 20

RISD without extinction, with differential reinforcement of manding.. 20

RISD without extinction (Pepsi ${ }^{\circledR}$ condition) and with extinction (attention condition), with differential reinforcement of manding............. 23

RISD with extinction, with differential reinforcement of manding.... 24

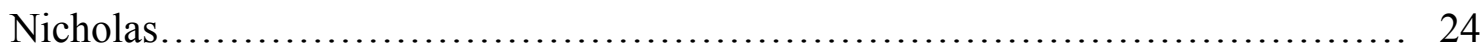

Functional analysis............................................ 24

Preference assessment.......................................... 24 
Testing the alternative stimulus.................................. 25

RISD without extinction, with differential reinforcement of manding....... 26

Chapter 3 - Conclusions ................................................. 28

General Discussion...................................................... 28

Effects of RISD Conditions on Problem Behavior............................. 28

Effects of RISD Conditions on Manding................................. 30

Effects of Extinction and its Implications on a Conceptual Analysis of RISD....... 31

References................................................................. 33

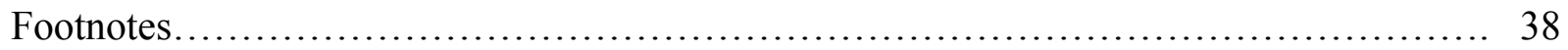


Chapter 1 - Overview

\section{Introduction}

Self-injurious behavior (SIB), severe aggression, and disruption are among the most challenging behaviors exhibited by individuals with autism or mental retardation. These behaviors adversely impact the individual's learning and independent functioning in the environment. If severe, challenging behaviors can threaten the health and safety of the individual and/or others.

Historically, behavioral interventions for the treatment of severe problem behavior often involved the manipulation of intense consequences, such as reinforcement (i.e., an increase in responding following delivery of, for example, edibles to a food-deprived individual) and punishment (i.e., a decrease in responding following delivery of, for example, water mist or electric shock) that potentially would compete with contingencies maintaining problem behavior. More recently, however, antecedent and ecological manipulations have become prevalent. Consequence-based interventions generally are more directly related to the manipulation of contingencies maintaining problem behavior than those used in the past, due primarily to the advent of functional assessment methods (Pelios, Morren, Tesch, \& Axlerod, 1999). Of the functional assessment methods, only the analog functional analysis (Iwata, Dorsey, Slifer, Bauman, \& Richman, 1982/1994) allows for causal statements about environment-behavior relations (Lerman \& Iwata, 1993), and thus it is used most often in empirical investigations. Since the development of this method, research has demonstrated that problem behavior can be maintained by social-positive attention (e.g., Hagopian, Fisher, \& Legacy, 1994), escape from unpleasant or aversive events (e.g., Vollmer, Marcus \& Ringdahl, 1995), access to a preferred tangible (e.g., Shirley, Iwata, \& Kahng, 1999), and automatic or sensory reinforcement (e.g., Roscoe, Iwata, \& Goh, 1998). Based on the results of a functional analysis, functionally-derived interventions can be developed to reduce the probability of subsequent problem behavior through systematic manipulation of antecedent and/or consequent variables related to problem behavior. Two commonly used interventions for problem behavior, for example, are functional communication training (FCT; Carr \& Durand, 1985) and noncontingent reinforcement (NCR; Vollmer, Iwata, Zarcone, Smith, \& Mazaleski, 1993). 


\section{Literature Review}

\section{Functional Communication Training}

Functional communication training is the differential reinforcement of an alternative behavior (DRA) that is functionally equivalent to problem behavior. This FCT is directly related to the outcome of the functional analysis. Carr and Durand (1985), for example, conducted a study with two children whose functional analyses suggested problem behavior was maintained by attention. They then taught a functionally-relevant mand: "Am I doing good work?" In response, trainers delivered 10-15 s of attention. Similarly, three children whose problem behavior was escape-maintained were taught the mand "I don't understand." Following the mand, trainers provided assistance. In both cases, problem behavior decreased considerably and manding increased.

Functional communication training is an effective intervention for problem behavior maintained by attention (e.g., Carr \& Durand, 1985), access to tangibles, (e.g., Hagopian, Fisher, Thibault Sullivan, Acquisto, \& LeBlanc, 1998), escape/avoidance (e.g., Lalli, Casey, \& Kates, 1995), and multiple factors (e.g., Hagopian et al.). Also, manding generalizes across setting and time. Durand and Carr (1991) demonstrated that decreases in problem behavior and increases in manding, achieved in one setting with one set of therapists, generalized across individuals and settings and were maintained over time. Durand and Carr (1992) further demonstrated the generality and utility of FCT by following several children for one year after treatment. They found that in comparison to participants whose problem behavior was followed by timeout, those who had learned functional mands exhibited increased generalization and maintenance.

Functional communication training has been used most often in combination with extinction (e.g., Shukla \& Albin, 1996) or punishment (e.g., Hagopian et al., 1998) of the problem behavior, and one of these treatments often is needed to adequately suppress problem behavior (e.g., Hagopian et al.; Wacker et al., 1990). Hagopian et al. reviewed 21 inpatient cases with whom FCT was used alone, with extinction, with extinction and demand fading/delay-toreinforcement, with positive punishment, and with positive punishment and fading/delay. Functional communication training without extinction or fading was unsuccessful in 11 cases; that is, it did not decrease problem behavior to at least $90 \%$ (it was not evaluated with the last ten participants due to lack of efficacy with the first 11). When FCT was applied with extinction, a 
$90 \%$ reduction in problem behavior was achieved in $44 \%$ of the applications without fading/delay and $41 \%$ of applications when fading/delay was instituted. Functional communication training with punishment was effective in $90 \%$ of the cases. Wacker et al. worked with inpatient participants emitting severe SIB and/or stereotypy and evaluated FCT with and without timeout. Functional communication training with and without timeout was evaluated with two participants and FCT with timeout was most effective at decreasing problem behavior. An alternative response of one participant, for example, decreased from $30 \%$ to $16 \%$ and hand biting increased from $0 \%$ to $18 \%$ when timeout was withdrawn.

In the aforementioned research on FCT, a functional analysis determined the maintaining reinforcer and a socially-appropriate mand instead was taught and reinforced. When these mands were reinforced in conjunction with extinction or punishment for problem behavior, problem behavior often was reduced. Without extinction or punishment, however, FCT produced mixed results (Hagopian et al., 1998; Wacker et al., 1990). Interventions containing extinction and/or punishment procedures, however, may be difficult for parents or teachers to implement consistently, making such procedures a less realistic option in the natural environment (Cooper, Heron, \& Heward, 1987; Miltenberger, 1997).

\section{Response-Independent Stimulus Delivery}

Noncontingent reinforcement (NCR) is the response-independent delivery of a preferred stimulus according to either a periodic (i.e., fixed-time; FT) or an aperiodic (i.e., variable-time; VT) schedule. The schedule of stimulus delivery is predetermined and when each interval elapses, the stimulus is delivered independently of responding (Vollmer et al., 1993). Originally used as a control procedure, NCR only recently has been used as an intervention for problem behavior (Vollmer et al., 1995). In the last decade, both the benefits and drawbacks of NCR as a treatment have been examined (e.g., Vollmer et al., 1993; Vollmer, Ringdahl, Roane, \& Marcus, 1997; see Tucker, Sigafoos, \& Bushell, 1998, for a review). Noncontingent reinforcement is effective in suppressing problem behavior when used alone and in combination with extinction or punishment. Although the stimulus delivered in NCR most often is the stimulus demonstrated to maintain problem behavior in an analog functional analysis, alternative (or "arbitrary") stimuli also have been used effectively. Noncontingent reinforcement will be referred to in the context 
of this paper as response-independent stimulus delivery (RISD). This change in terminology is warranted by the misuse of the term "reinforcement" in the former phrase. Because reinforcement, by definition, involves response-dependent delivery or removal of a stimulus and a subsequent increase in rate or occurrence of some behavior, and NCR does not include this component (but instead actually decreases the likelihood of a behavior), RISD is more appropriate (Poling \& Normand, 1999; Vollmer, 1999).

\section{Basic research}

In basic research, RISD generally has been found to decrease response rates (e.g., Burgess \& Wearden, 1986; Lattal, 1972; Sizemore \& Lattal, 1977; Zeiler, 1968). Sizemore and Lattal, for example, compared immediate reinforcement, unsignaled delayed reinforcement, and RISD and found that response rates were lowest in the RISD condition. Specifically, a VT schedule of food delivery occurred in the RISD condition and produced decreased response rates relative to variable-interval (VI) schedules arranging immediate and delayed reinforcement. Response rates eventually reached near-zero levels in the VT-schedule condition. Burgess and Wearden reviewed studies showing response suppression following the superimposition a VT schedule on an existing response-dependent schedule. A full review of the basic literature on RISD is beyond the scope of this paper; however, the results of these and other studies are important as they have applied implications in the examination of RISD and its relation to problem behavior - findings of basic research may demonstrate how applied researchers might decrease problem behavior in participants. In applied research, as demonstrated by Vollmer et al. (1993), the response-independent delivery of a reinforcing stimulus reduces rates of the target response, as it does in basic research.

\section{RISD of the maintaining reinforcer}

Response-independent stimulus delivery first was used as an intervention by Mace and Lalli (1991). They used RISD to suppress the attention-maintained bizarre speech of one participant. Subsequently, studies investigating the utility of RISD of the maintaining reinforcer in applied settings have used both continuous reinforcement (e.g., Roscoe et al., 1998) and schedules of reinforcement based on baseline levels of problem behavior (e.g., Kahng, Iwata, DeLeon, \& Wallace, 2000). Both methods have been shown to decrease rates of problem 
behavior, and there are several reasons why RISD might have this effect. First, the frequent response-independent delivery of the reinforcer maintaining the problem behavior might eliminate its establishing operation (cf. Michael, 1982) through satiation (Vollmer et al., 1993). Second, the independent delivery of the reinforcer disrupts the correlation between the behavior and the reinforcer (Vollmer et al., 1993; 1995) as the reinforcer occurs regardless of whether or not the behavior occurs. Third, matching theory has been implicated due to the availability of other reinforcers (Hagopian, Crockett, van Stone, DeLeon, \& Bowman, 2000). According to matching, responding to different alternatives is a proportion of how reinforcement is distributed across various alternatives (Herrnstein, 1961). In the case of RISD, as responding is allocated toward the stimulus being delivered response independently, less responding is necessarily allocated toward problem behavior.

Response-independent stimulus delivery has been employed both with extinction (e.g., Vollmer et al., 1993; Vollmer et al., 1995; Hagopian et al., 1994) and without (e.g., Lalli, Casey, and Kates, 1997); however, it most commonly is used in conjunction with extinction. When RISD is used in combination with extinction, the maintaining reinforcer is delivered independently of the response so that problem behavior has no programmed consequence. Thus, it is difficult to separate the effects of RISD from those typically correlated with extinction in that it is unclear if the decrease in responding is due to extinction alone or if it is due to RISD. Also, it is unclear whether RISD alone results in response suppression. Several studies have used RISD without extinction and have produced mixed results. To illustrate, Lalli et al. evaluated RISD without extinction with one participant. The maintaining reinforcer was delivered response independently, but also contingent upon the occurrence of the problem behavior. There was an initial increase in problem behavior, followed by its suppression. Hagopian et al. (2000), however, also assessed RISD without extinction with three participants, and it was effective when there was continuous access to the stimulus, but problem behavior increased when the rate of delivery of the stimulus was decreased-extinction was necessary to suppress responding.

\section{RISD of an alternative stimulus}

Several recent studies have examined the response-independent delivery of an alternative stimulus (i.e., a stimulus that was not identified as maintaining the problem behavior). This 
stimulus is identified as "preferred" in a stimulus preference assessment, but does not increase rates of problem behavior when delivered contingently, as the maintaining reinforcer would. The advantage of using alternative stimulus delivery is that RISD may be implemented even if the maintaining reinforcer cannot be identified or manipulated (e.g., problem behavior is maintained by sensory reinforcement) or if problem behavior is multiply maintained. Additionally, the alternative stimulus may be delivered if the maintaining reinforcer is impossible, impractical, or inconvenient to use.

Four studies (Fischer, Iwata, \& Mazaleski, 1997; Fisher et al., 2000; Hanley, Piazza, \& Fisher, 1997; Roscoe et al., 1998) have demonstrated the efficacy of RISD with an alternative stimulus. Fischer et al., for example, evaluated the utility of RISD with alternative stimuli with two participants. Alternative stimuli were selected based on the results of a systematic preference assessment after the maintaining reinforcer for problem behavior was identified through an analog functional analysis. The preference assessment was based on procedures described by Fisher et al. (1992). Maintaining reinforcers were attention for one participant and access to tangibles (shoes) for the other. Alternative stimuli were different types of food for each participant, delivered dependent on a response in the testing phase. These stimuli were tested against the baseline functional analysis condition to determine if their dependent presentation would increase rate of responding. Because responding did not increase when the food was presented response dependently, it was considered to be an alternative stimulus not responsible for behavior maintenance. In the RISD conditions, baseline was similar to that condition in the functional analysis in which rates of problem behavior were highest (i.e., attention or tangible). In the treatment conditions, RISD occurred on an FT 10-s schedule, and the maintaining reinforcer was delivered on a fixed-ratio (FR) 1 schedule (RISD without extinction). Responding decreased in this condition for both participants, but when the RISD schedule was leaned, SIB was put on extinction a priori. In the fading process, one delivery per min was eliminated as long as rate of SIB was at or below 0.5 responses per min. Results for one participant were inconclusive; SIB rates varied and the schedule of reinforcement was not faded beyond one delivery per min. For the other participant, response-independent delivery of the alternative stimulus with and without extinction of the problem behavior suppressed SIB. 
Hanley et al. (1997) compared RISD with alternative stimuli to RISD with the maintaining stimulus (attention) using an alternating treatments design with two individuals exhibiting problem behavior maintained by attention. In each condition, there were no programmed consequences following problem behavior (i.e., extinction). Both interventions were equally effective in reducing problem behavior. To evaluate the generality of RISD with alternative stimuli, Fisher et al. (2000) conducted a systematic preference assessment to identify a highly-preferred and a less-preferred stimulus for a participant diagnosed with cerebral palsy. Next, both items were made available throughout separate conditions in a multielement design; attention (the maintaining reinforcer) was delivered on an FR1 schedule (extinction was not implemented). Suppression occurred in the condition with the delivery of the high-preference stimulus, but not with the delivery of the low-preference stimulus.

More research is needed to identify the operative mechanisms of response-independent delivery of an alternative stimulus. Of the interpretations offered earlier for the efficacy of RISD, matching theory (Hagopian et al., 2000) is the only one that accounts for the efficacy of RISD of an alternative stimulus as the stimulus being delivered is not the one maintaining the behavior or increasing the likelihood of the problem behavior. Explanations appealing to satiation cannot account easily for these findings. Support for these conclusions will be detailed below (see General Discussion).

\section{RISD Compared to Differential Reinforcement}

Response-independent stimulus delivery often is compared to and contrasted with differential reinforcement procedures with regard to efficacy and ease of implementation. Vollmer et al. (1993) noted that differential reinforcement of other behavior (DRO), generally considered to be an effective intervention overall, has several drawbacks limiting its utility. First, DRO is less effective in extremely severe cases of SIB and aggression. Second, an extinction burst may occur. Finally, it is considered difficult to train therapists, teachers, and parents to implement DRO due to the constant vigilance that is required.

Vollmer et al. (1993) compared DRO to RISD with extinction with three participants exhibiting SIB maintained by attention. The authors used a multielement design and multiple baseline across-subjects design for two participants; an ABAC reversal was implemented for the 
third participant. In one treatment condition, a resetting DRO 10-s schedule was implemented which was gradually increased across sessions. Response-independent delivery, using the maintaining reinforcer, was implemented in the second treatment condition and was faded from 6 to 0.2 per min across sessions. Near-equal suppression of SIB in both DRO and RISD conditions occurred with each participant and, for two of three participants, more rapid decrement of problem behavior occurred in the RISD condition. For one participant, reductions under RISD were more delayed; however, further analysis revealed that she exhibited significantly fewer instances of extinction-related responses in the RISD condition than she did when DRO was in effect (e.g., crying).

\section{RISD with FCT}

Response-independent stimulus delivery has been used concurrently with FCT techniques in two studies (Goh, Iwata, \& DeLeon, 2000; Marcus \& Vollmer, 1996). With all three participants, Marcus and Vollmer found that the FT delivery of the maintaining reinforcer did not inhibit manding. The participants obtained reinforcers on an FT schedule, and on an FR1 for an appropriate mand. There were no programmed consequences for the occurrence of the problem behavior (i.e., extinction). Problem behavior decreased and manding increased. These results occurred whether the RISD component was in effect before or after the mands were reinforced (different treatments were imposed with different subjects). It is difficult to interpret these results as the RISD schedule was leaned rapidly and manding increased as the schedule was leaned. Therefore, it is unclear as to whether manding would have occurred on a denser schedule of RISD.

Goh et al. (2000) further evaluated the relation between RISD and manding; however, they attempted to control for the potential effects of quickly decreasing the schedule of stimulus delivery. Specifically, Goh et al. implemented RISD on a dense schedule for extended periods [rather than quickly initiating fading, as was done in the Marcus and Vollmer (1996) study]. Although SIB decreased substantially, mands did not reliably occur until the rate of responseindependent delivery was decreased. Goh et al. suggested that the failure to mand reliably might have occurred because RISD resulted in satiation, and both problem behavior and alternative behaviors (i.e., mands) thus were suppressed. 
Statement of the Problem

Research has examined either the impact of FCT with RISD of the maintaining reinforcer or response-independent delivery of an alternative stimulus (instead of the maintaining reinforcer) on rates of problem behavior. Although tentative, results to date suggest that manding might not occur reliably until the RISD schedule is leaned. Further, the extent to which extinction is necessary when RISD is combined with FCT is unclear. Research has demonstrated the utility of RISD with an alternative stimulus but RISD with an alternative stimulus and FCT have not yet been combined. In such a paradigm, if extinction is used, mands are likely to increase as the reinforcer maintaining problem behavior is not otherwise obtained under extinction. It also is possible, however, that extinction is unnecessary as rates of problem behavior may decrease as a result of RISD, with the maintaining reinforcer dependent on manding. Such an intervention would improve on existing RISD interventions because alternative behaviors would be reinforced explicitly. Also, the RISD component should reduce

extinction bursts. Additionally, the possibility of utilizing RISD without an extinction component has valuable implications - it would be easier for parents and teachers to implement in that, rather than having to consistently extinguish behavior, they would continue delivering consequences in the same manner as previously. The purpose of the present study, then, was to determine if RISD of an alternative stimulus still was effective in reducing rates of problem behavior without implementing extinction. Additionally, this study examined the extent to which participants emitted mands resulting in the maintaining reinforcer when the alternative stimulus was delivered concurrently independently of responding.

Chapter 2 - Experimental Methods and Results

\section{Method}

\section{Participants and Setting}

Participants were two children with developmental delays exhibiting problem behavior (e.g., self-injury, aggression, disruption). Only those individuals whose behavior was determined to be maintained by attention through an analog functional analysis (described below) participated. Individuals whose problem behavior was multiply maintained could participate unless access to tangibles was identified as a reinforcer. Three additional children initially were 
included but then were eliminated as the functional analysis suggested that problem behavior was not maintained by social positive reinforcement or that behavior was maintained by access to both attention and tangibles. Logan was a 13-year-old male with mild to moderate mental retardation who exhibited SIB, aggression, and property destruction. Logan followed simple oneand two-step directions. Logan frequently emitted vocalizations but had few intelligible words. He used about ten functional signs to communicate.

Nicholas was a two-year-old male with global developmental delays. Cognitive and adaptive behavior evaluations were not completed for Nicholas, but he appeared to be functioning in the severe to profound range of mental retardation. Nicholas was nonambulatory and had no vocal language. He emitted one modified expressive sign for "more." Nicholas exhibited SIB, aggression, and disruptive behavior.

Sessions for Logan were conducted at a speech and language clinic in a town close to his home where he received speech and language services several times per week. His sessions were conducted in a room containing two tables, two chairs, office materials, a locked cabinet, and toys and materials relevant to the session. Sessions for Nicholas were conducted in a clinic room at the Department of Psychology at West Virginia University. The room was empty except for materials relevant to the session. Sessions conducted with both participants lasted $10 \mathrm{~min}$ and were conducted for approximately four to six hours per day, approximately three days per week (for Logan) or two to four hours per day, approximately two days per week (for Nicholas).

\section{Experimental Design}

The study consisted of three phases: functional analysis, preference assessment, and evaluation of RISD. An alternating treatments design was used to compare the effects of RISD of the maintaining reinforcer with RISD of the alternative stimulus.

\section{Response Definitions, Data Collection, and Interobserver Agreement}

Frequency of aggression, SIB, disruption, and manding were coded using a continuous recording system. Aggression was defined as (a) biting-closure of the upper and lower teeth around the skin of another person (Logan), (b) hitting-forceful contact between an open hand and the body of another person (Logan and Nicholas), (c) pinching-closure of the fingers and thumb around the skin of another person (Logan and Nicholas), (d) scratching-dragging the fingernails across the skin of another person (Logan and Nicholas), (e) throwing-throwing objects landing 
within $1 \mathrm{ft}$ of another person (Logan), and (f) hair pulling-grasping the hair of another person and pulling (Logan and Nicholas). SIB was defined as head banging-forceful contact between the head and the wall, floor, or another object loud enough to be heard (Logan and Nicholas), (b) biting-closure of the upper and lower teeth around one's own skin (Logan), (c) hitting-forceful contact between an open hand and one's own body (Logan), and (d) pinching-closure of the fingers and thumb around one's own skin (Logan and Nicholas). Disruption was defined as (a) screaming-high-pitched sound, louder than normal conversational tone, and lasting no more than 1-2 s (Nicholas), (b) throwing objects-throwing objects not designed for throwing (Logan), (c) banging objects-forcefully banging two objects together or one object into the wall or floor loud enough to be heard (Logan), and (d) overturning objects-upsetting large objects (e.g., table, chair) from their rightful, upright position (Logan). Mands were defined as a completed picture icon exchange including: reaching for the icon, grasping the icon, putting the icon in the therapist's hand, and releasing the icon (Logan and Nicholas). Therapist behaviors also were coded, and varied depending on the condition. Definitions of therapist responses are in Table 1. Sessions were videotaped for later coding by trained graduate and undergraduate students. Data collectors were trained in the coding system and data were coded on desktop or handheld computers using a real-time data collection program (Observer) installed in desktop and Psion hand-held computers.

Prior to initiating data collection, observers were trained to criterion. Training involved a demonstration by the primary investigator followed by practice sessions. During practice sessions, observers coded sample videotapes of other children exhibiting similar topographies of behavior in an analog functional analysis. The observers were required to reach $80 \%$ or higher agreement for all target responses for three consecutive sessions prior to the start of data collection for the present study. Interobserver agreement was assessed in approximately $30 \%$ of the sessions by having two observers collect data independently but concurrently. Agreement was calculated by partitioning sessions into continuous 10-s intervals and comparing observers' records on an interval-by-interval basis. Within each interval, the smaller number of responses was divided by the larger number, and the resulting proportions were averaged across intervals to obtain a percentage agreement score. Mean agreement scores are listed in Table 2. 
Table 1

Therapist Responses during Functional Analysis

Condition Antecedent

Demand

\begin{tabular}{|c|c|}
\hline Fixed-time delivery & Verbal prompt \\
\hline $\begin{array}{l}\text { Noncompliance to } \\
\text { verbal prompt }\end{array}$ & Gestural prompt \\
\hline $\begin{array}{l}\text { Noncompliance to } \\
\text { gestural prompt }\end{array}$ & Physical prompt \\
\hline Target response & Removal of task \\
\hline $\begin{array}{l}\text { Compliance to verbal } \\
\text { or gestural } \\
\text { prompts }\end{array}$ & Attention delivery \\
\hline
\end{tabular}

Attention

Target response Attention delivery

Tangible

Control

Fixed-time passage
Tangible delivery

Tangible removal

Fixed-time delivery
Vocal instruction (e.g., "Clap).

Vocal instruction paired with modeling (e.g., "Clap," while the therapist claps).

Vocal instruction paired with physical guidance for the child to complete the task (e.g., "Clap," while the therapist moves

the child's hands together in a clapping motion).

Withdrawal of task materials and break in eye contact lasting $20 \mathrm{~s}$.

Brief vocal response related to task (e.g., "Good clapping") and/

or brief physical contact (e.g., tickle) lasting $3 \mathrm{~s}$.

Brief vocal response related to target response (e.g., "Don't don't do that") and/or brief physical contact lasting $3 \mathrm{~s}$

Preferred item delivered to child for $20 \mathrm{~s}$.

Preferred item withdrawn from child.

Brief vocal and/or physical response lasting $3 \mathrm{~s}$. Vocal responses consist of play-related or praising statements (e.g., "Nice playing"), play statements (e.g., "Look, the car goes 'vrooom vrooom'), and/or social comments (e.g., "I'm so glad you came to play with me today"). 
Table 2

Mean Agreement Scores for Child and Adult Responses

Participant Condition

Logan

Analog

Baseline

$\begin{array}{lll}\text { Problem Behavior } & \text { Prompt } & \text { Attention Delivery } \\ 97 \%(90 \%-100 \%) & 99 \%(97 \%-100 \%) & 97 \%(98 \%-100 \%) \\ \text { Tangible Delivery } & \text { Escape } & \text { Tangible Removal } \\ 99 \%(98 \%-100 \%) & 97 \%(87 \%-100 \%) & 100 \%\end{array}$

Problem Behavior Stimulus Delivery

Treatment $89.2 \%(89 \%-89.4 \%) \quad 88.7 \%(88 \%-89.4 \%)$

$\begin{array}{lll}\text { Problem Behavior } & \text { Stimulus Delivery } & \text { Manding } \\ 92.93 \%(85.4 \%- & & \\ 100 \%) & 90.77 \%(84.67-100 \%) & 96.18 \%(92.5 \%-100 \%)\end{array}$

Nicholas

Analog

$\begin{array}{ll}\text { Problem Behavior } & \text { Prompt } \\ 98.54 \%(98.33 \%- & \\ 99.17 \%) & 93.88 \% \\ \text { Tangible Delivery } & \text { Escape } \\ 100 \% & 100 \%\end{array}$

Attention Delivery

$98.13 \%(96.67 \%-100 \%)$

Tangible Removal

$98.34 \%(96.67-100 \%)$

Baseline

Problem Behavior Stimulus Delivery

95.15\% (86\%-100\%) 95.33\% (86\%-100\%)

Treatment

$\begin{array}{lll}\text { Problem Behavior } & \text { Stimulus Delivery } & \text { Manding } \\ 98.35 \%(95.83 \%- & & \\ 100 \%) & 96.68 \%(88.3 \%-100 \%) & 99.01 \%(96.67 \%-100 \%)\end{array}$




\section{Procedure}

Phase 1: Functional analysis

A functional analysis similar to that described by Iwata et al. (1982/1994) was conducted with each participant. It included four conditions: demand, attention, tangible, and control. Conditions were conducted in semirandom order, with no single condition occurring twice in succession. Each session lasted $10 \mathrm{~min}$. Sessions were conducted until responding was judged to be stable through visual inspection. If the physical safety of either the participant or the therapist was threatened at any time, the session was discontinued and eligibility re-evaluated. Sessions were terminated early twice for Logan because he bit the therapist. The therapist was re-trained in safety measures, and Logan remained in the study until completion. With Nicholas, Phase A (extinction) of the testing condition was terminated prior to meeting stability criteria at parental request (due to head banging).

In the demand condition, the therapist sat with the client at a table and presented preacademic demands using a three-step prompting procedure consisting of sequential verbal, gestural, and physical prompts. The purpose of the demand condition was to determine if problem behavior was maintained by escape or avoidance. The child received brief verbal praise upon successful completion of the task (i.e., compliance). If the child exhibited a targeted problem behavior (e.g., aggression), the task was withdrawn for $20 \mathrm{~s}$ and the therapist turned away from the client. After the 20 -s interval, a new demand was presented. All behaviors were ignored during the 20 -s interval. At the beginning of the attention condition, the therapist told the child, "Play with your toys, I have some work to do," and looked at a magazine. Contingent upon and immediately following a problem behavior, the therapist delivered a brief verbal reprimand (e.g., "stop that," or "don't hit"). All other behaviors were ignored. The purpose of the attention condition was to determine if problem behavior was maintained by access to attention. In the tangible condition, the child was given a preferred tangible for $2 \mathrm{~min}$ prior to the start of the session. When the session began, the item was removed. Immediately following problem behavior, the tangible was returned to the child for $20 \mathrm{~s}$. The purpose of the tangible condition was to determine if problem behavior was maintained by access to preferred tangibles. In the control condition, the therapist was present and preferred toys were available. The therapist delivered verbal attention (i.e., praise) every $20 \mathrm{~s}$ on a schedule of RISD. This condition 
controlled for the absence of demands, the attention of the therapist, and the presence of tangibles.

\section{Phase 2: Preference assessment}

Preference assessments to identify preferred stimuli were conducted based on the procedure of Fisher et al. (1992). Parents were asked to generate a list of five edible items preferred by the participant. Due to a restricted diet, only three items were selected for Nicholas. Items were presented in pairs such that each item was presented once with every other item. Pairs of stimuli were placed in front of the participant, approximately $0.5 \mathrm{~m}$ from him and approximately $0.7 \mathrm{~m}$ apart. Data were recorded on which of the two items the participant approached first. An approach was defined as reaching toward and/or contacting the tangible. The participant was permitted to consume the item approached. After approach to one stimulus, the other stimulus was removed immediately. Attempts to approach both stimuli simultaneously were blocked physically. If the child did not approach either of the stimuli after $5 \mathrm{~s}$, he was physically prompted to sample the items, which then were placed back on the table for $5 \mathrm{~s}$. If neither item was approached during the second trial, the items were removed from the table, and the next two items were placed on the table for assessment. This assessment allowed the items to be rank-ordered in terms of preference. The most highly preferred item was used as the alternative stimulus for each child in subsequent phases.

\section{Phase 3: Evaluation of RISD}

Testing the alternative stimulus. Prior to evaluating the effects of delivering the alternative stimulus response independently (RISD with alternative stimulus), an assessment was conducted to determine whether the stimuli actually were arbitrary (i.e., did not maintain problem behavior). An AB design was used, in which A was baseline and B was testing. All sessions were conducted in a session room in which alternative stimuli were delivered through an open window (for Logan) or an ajar door (for Nicholas). The individual delivering the alternative stimuli remained out of sight throughout the assessment. In baseline, no programmed consequences followed problem behavior. In the testing condition, the alternative stimulus, derived from stimulus preference assessment, was delivered dependent on and immediately following the occurrence of a targeted problem behavior. For Logan, the therapist delivered

Pepsi Cola ${ }^{\circledR}$ by reaching through the window and placing it on a table. For Nicholas, the therapist 
delivered oatmeal by putting a spoon through the open door. (Nicholas did not walk and consequently was placed in front of the door at the start of each session). Data were collected on the frequency of problem behavior to determine if the alternative stimulus was a reinforcer.

Functional communication training. The participants were taught to hand the experimenter a picture card. This exchange was followed by attention delivery. For each participant, training involved systematically fading physical guidance of picture exchange icons. This training involved two experimenters - one who initiated the trial, and the other who physically guided the picture exchange. Physical guidance was faded from full physical prompts to partial physical prompts, to gestural prompts, to no prompts based on $90 \%$ accuracy of each step across three sessions. Functional communication training was completed in six sessions for Logan and three sessions for Nicholas.

RISD, without extinction, with differential reinforcement of manding. After completion of FCT, evaluation of RISD commenced. An alternating treatments design compared responseindependent delivery of the maintaining reinforcer (i.e., attention; hereafter, the attention condition) with response-independent delivery of the alternative stimulus (Pepsi ${ }^{\circledR}$ for Logan, oatmeal for Nicholas). To increase the likelihood that stimulus control would develop for both conditions, different therapists implemented each condition with Logan. For Nicholas, the same therapist implemented the different conditions, but wore a long blue lab coat only in the attention condition.

Baseline for this phase was similar to the attention condition of the functional analysis. That is, problem behavior was reinforced with attention on an FR1 schedule. After responding stabilized in baseline, the comparison of FT delivery of the alternative stimulus and the maintaining reinforcer was initiated. Throughout this phase, problem behavior and the target mand were reinforced on an FR1 schedule with the maintaining reinforcer. The initial FT schedule for stimulus delivery (either the alternative stimulus or the maintaining reinforcer) was yoked from the mean rate of problem behavior in baseline. The rate of stimulus delivery was decreased based on continued suppression of problem behavior. Suppression for Logan was defined as an $80 \%$ reduction in problem behavior relative to baseline for two consecutive sessions. The rate of stimulus delivery for Nicholas was decreased when rates of problem behavior were decreased by at least $75 \%$ for two consecutive sessions relative to baseline. 
("Success" criteria were different for each participant due to highly differential baseline rates of responding.) For Logan, rates of stimulus delivery were decreased by adding fixed increments of $10 \mathrm{~s}$ based on suppression; for Nicholas, rates of stimulus delivery were decreased by adding fixed increments of $5 \mathrm{~s}$ based on suppression. If problem behavior increased above the predetermined criterion (i.e., $80 \%$ of baseline for Logan, $75 \%$ for Nicholas) for two consecutive sessions, then the RISD-schedule value returned to its previous value. For example, problem behavior occurred an average of 38.16 responses per min in baseline for Logan. His schedule was faded when problem behavior remained below 7.63 responses per min for two consecutive sessions. If problem behavior occurred at rates above two responses per min for two consecutive sessions, the RISD schedule was decreased. For both participants, successful intervention was defined as suppression of problem behavior below $80 \%$ of baseline (75\% for Nicholas) and the schedule of stimulus delivery was decreased to one delivery occurring every $1 \mathrm{~min}$.

RISD, with extinction and differential reinforcement for manding. Because the RISD schedule was not faded to $1 \mathrm{~min}$ for Logan, extinction was implemented. In extinction, RISD continued as described above. The FT schedule began at the last interval at which response suppression was maintained at $80 \%$ below baseline. Specifically, Logan's rate of problem behavior remained below $20 \%$ of that observed in baseline when RISD was an FT 20-s schedule; responding increased above that criteria, however, when the rate of delivery was decreased to an FT 30-s schedule. Thus, extinction initially was implemented for the attention condition on an FT 20-s schedule. Decreasing the rate of stimulus delivery continued as just described and manding was reinforced on an FR1 schedule.

\section{Results and Discussion}

For Logan and Nicholas, results of the analog functional analyses are depicted in Figures 1 and 4, respectively. Rates of problem behavior during testing of the alternative stimulus are depicted in Figures 2 and 5, respectively. Results obtained during RISD with differential reinforcement of manding are depicted in Figures 3 and 6, respectively. The top graphs in Figures 5 and 6 depict rates of problem behavior, and the bottom graphs in Figures 5 and 6 depict rates of manding. The schedule of stimulus delivery used during each session is listed in Table 3 for Logan and Table 4 for Nicholas. 
Table 3

Schedule of Stimulus Delivery for Logan

\begin{tabular}{|c|c|c|c|c|c|c|c|}
\hline Session & $\begin{array}{l}\text { Attention } \\
\text { Condition }\end{array}$ & Pepsi Condition & Session & $\begin{array}{l}\text { Attention } \\
\text { Condition }\end{array}$ & Pepsi Condition & Session & $\begin{array}{l}\text { Attention } \\
\text { Condition }\end{array}$ \\
\hline 11 & & FT10" & 44 & FT10" & & 77 & \\
\hline 12 & CRF & & 45 & & FT60" & 78 & \\
\hline 13 & & CRF & 46 & FT20" & & 79 & FT60"EXT \\
\hline 14 & CRF & & 47 & & FT50" & 80 & FT60"EXT \\
\hline 15 & & FT10" & 48 & FT20" & & 81 & FT60"EXT \\
\hline 16 & CRF & & 49 & & FT50" & 82 & \\
\hline 17 & & FT20" & 50 & FT30" & & 83 & \\
\hline 18 & CRF & & 51 & & FT60" & 84 & \\
\hline 19 & & FT20" & 52 & FT30' & & 85 & FT60"EXT \\
\hline 20 & CRF & & 53 & & FT60' & 86 & FT60"EXT \\
\hline 21 & & FT20" & 54 & FT20"EXT & & 87 & FT60"EXT \\
\hline 22 & CRF & & 55 & & FT60" & 88 & \\
\hline 23 & & FT20" & 56 & FT20"EXT & & 89 & \\
\hline 24 & FT10" & & 57 & & FT60" & 90 & \\
\hline 25 & & FT20" & 58 & FT30"EXT & & 91 & FT60"EXT \\
\hline 26 & FT10" & & 59 & & FT50" & 92 & FT60"EXT \\
\hline 27 & & FT30" & 60 & FT30"EXT & & 93 & FT60"EXT \\
\hline 28 & FT10" & & 61 & & FT50" & 94 & \\
\hline 29 & & FT30" & 62 & FT40"EXT & & 95 & \\
\hline 30 & FT10" & & 63 & & FT40" & 96 & \\
\hline 31 & & FT30" & 64 & FT40"EXT & & 97 & FT60"EXT \\
\hline 32 & CRF & & 65 & & FT40" & 98 & FT60"EXT \\
\hline 33 & & FT40" & 66 & FT50"EXT & & 99 & FT60"EXT \\
\hline 34 & CRF & & 67 & & FT30" & 100 & \\
\hline 35 & & FT40" & 68 & & FT30" & 101 & \\
\hline 36 & CRF & & 69 & & FT20" & 102 & \\
\hline 37 & & FT40" & 70 & & FT20" & 103 & FT60"EXT \\
\hline 38 & CRF & & 71 & & FT10" & 104 & FT60"EXT \\
\hline 39 & & FT50" & 72 & & FT10" & 105 & FT60"EXT \\
\hline 40 & FT10" & & 73 & FT50"EXT & & 106 & \\
\hline 41 & & FT50" & 74 & FT60"EXT & & 107 & \\
\hline 42 & FT10" & & 75 & FT60"EXT & & 108 & \\
\hline 43 & & FT60" & 76 & & FT10"EXT & & \\
\hline
\end{tabular}


Table 4

Schedule of Stimulus Delivery for Nicholas

\begin{tabular}{|c|c|c|c|c|c|}
\hline $\begin{array}{c}\text { Session } \\
11\end{array}$ & $\begin{array}{l}\text { Attention } \\
\text { Condition }\end{array}$ & $\begin{array}{c}\text { Oatmeal } \\
\text { Condition } \\
\text { FT7"'" }\end{array}$ & $\begin{array}{c}\text { Session } \\
34\end{array}$ & $\begin{array}{l}\text { Attention } \\
\text { Condition }\end{array}$ & $\begin{array}{c}\text { Oatmeal } \\
\text { Condition } \\
\text { FT32" }\end{array}$ \\
\hline 12 & FT7" & & 35 & FT7" & \\
\hline 13 & FT7" & & 36 & & FT32" \\
\hline 14 & & FT7" & 37 & & FT37" \\
\hline 15 & FT7" & & 38 & FT7" & \\
\hline 16 & & FT7" & 39 & & FT37" \\
\hline 17 & & FT12" & 40 & & FT42" \\
\hline 18 & FT7" & & 41 & & FT42" \\
\hline 19 & FT7" & & 42 & FT12" & \\
\hline 20 & & FT17" & 43 & FT12" & \\
\hline 21 & & FT17" & 44 & & FT42" \\
\hline 22 & FT7" & & 45 & & FT37" \\
\hline 23 & & FT22" & 46 & FT7" & \\
\hline 24 & & FT22" & 47 & & FT37" \\
\hline 25 & & FT27" & 48 & & FT37" \\
\hline 26 & FT7" & & 49 & & FT37" \\
\hline 27 & & FT27" & 50 & FT7" & \\
\hline 28 & FT12" & & 51 & FT7" & \\
\hline 29 & & FT32" & 52 & FT7" & \\
\hline 30 & FT12" & & 53 & & FT37" \\
\hline 31 & FT12" & & 54 & & FT32" \\
\hline 32 & FT12" & & 55 & & FT32" \\
\hline 33 & & FT32" & & & \\
\hline
\end{tabular}


Logan

Functional analysis

Results of the analog functional analysis conducted with Logan are depicted in Figure 1. Logan emitted problem behavior almost exclusively during the attention condition $(M=48.1)^{1}$, suggesting that it was maintained by social positive reinforcement (i.e., attention).

Preference assessment

Logan was presented with Pepsi ${ }^{\circledR}$, yogurt, cheese, Tater Tots ${ }^{\circledR}$, and chips. In the preference assessment, Logan exclusively chose Pepsi ${ }^{\circledR}$ when it was offered. Thus, Pepsi ${ }^{\circledR}$ was the stimulus tested in the testing phase.

\section{Testing the alternative stimulus}

Results of alternative stimulus testing for Logan are depicted in Figure 2. Rates of problem behavior during baseline (extinction of problem behavior) ranged from 0 to 1.3 responses per $\min (M=0.34)$. Rates of problem behavior when Pepsi was delivered response dependently ranged from 0 to 0.6 responses per $\min (M=0.30)$. Although rates of problem behavior were somewhat variable, response-dependent delivery of Pepsi ${ }^{\circledR}$ did not increase responding systematically relative to baseline. Anecdotally, responding in the testing phase seemed to be reinforced more by inadvertent attention from the individual delivering the Pepsi ${ }^{\circledR}$ rather than by soda per se. Pepsi ${ }^{\circledR}$ was used as the alternative stimulus throughout the remainder of the study. RISD, without extinction, with differential reinforcement of manding

Results obtained with Logan are depicted in Figure 3. Problem behavior is depicted in the top graph and manding in the bottom graph. Two different therapists conducted baseline and treatment sessions with Logan. The first therapist was correlated with Pepsi ${ }^{\circledR}$ delivery in treatment, and the second therapist delivered attention on an FT schedule. In baseline, rates of problem behavior did not differ significantly between therapists ( $M=40.18$ for one therapist; $M=36.14$ for the second therapist). Due to Logan's high rates of problem behavior in baseline, Logan's initial RISD schedule for both attention and Pepsi began on a continuous schedule of reinforcement (CRF). 


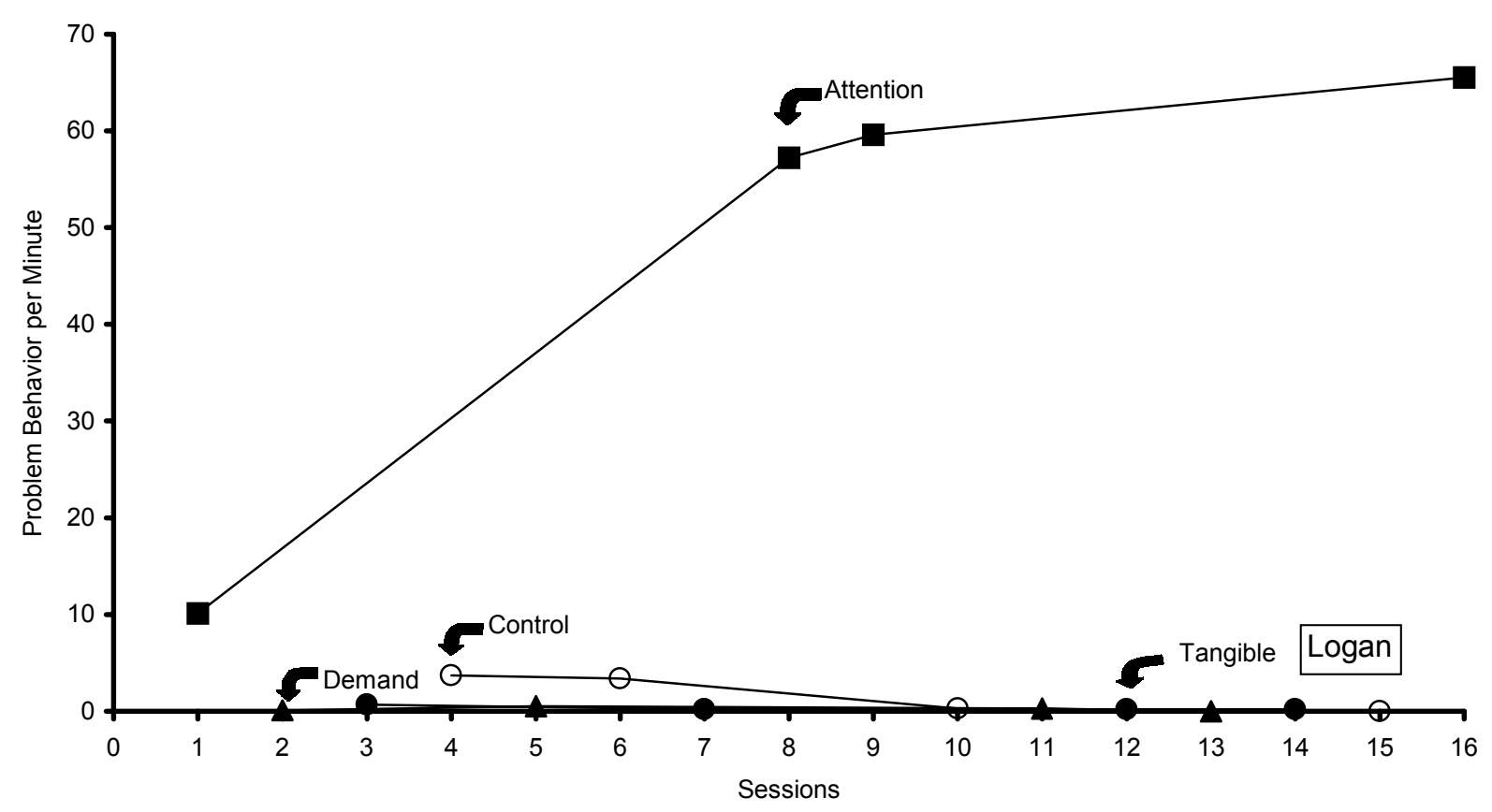

Figure 1. Rates of problem behavior during functional analysis for Logan.

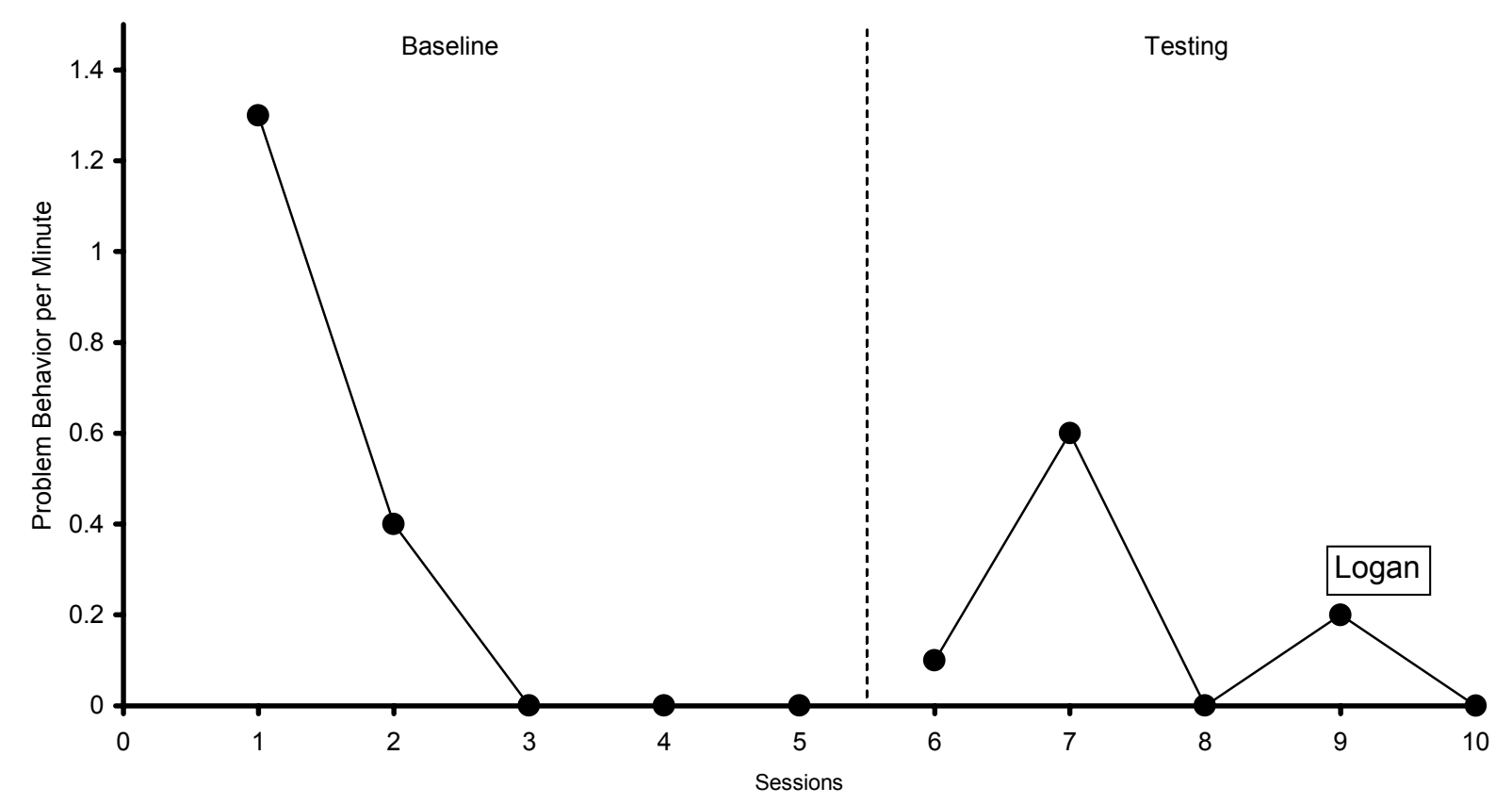

Figure 2. Rates of problem behavior during alternative-stimulus testing condition for Logan. 


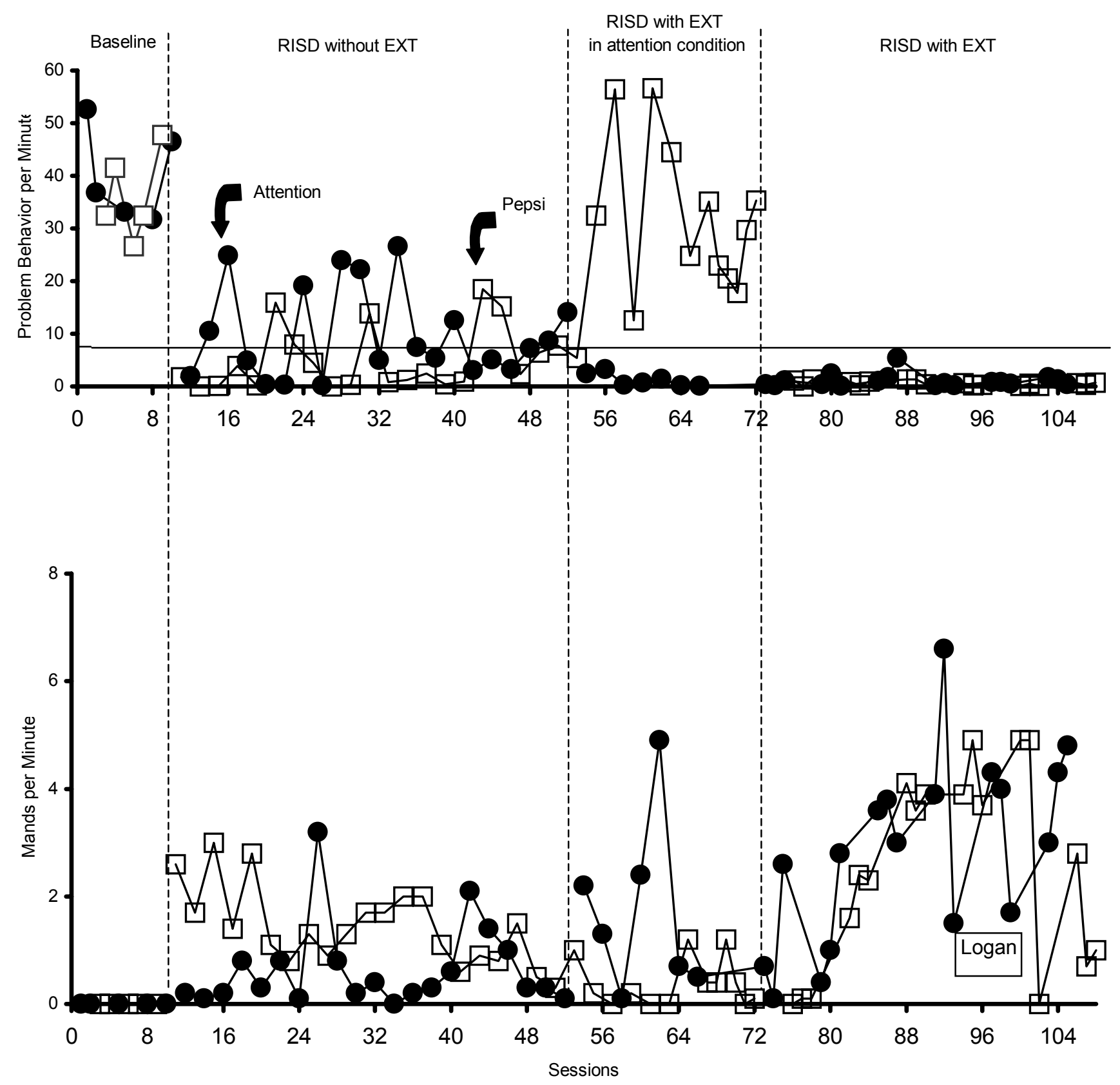

Figure 3. Rates of problem behavior and manding during evaluation of response-independent stimulus delivery for Logan. 
Once RISD was initiated, rates of problem behavior in sessions where Pepsi ${ }^{\circledR}$ was delivered on the FT schedule remained below the criterion for fading ( $80 \%$ reduction relative to baseline; indicated by the horizontal line) for the first 5 sessions. By the $5^{\text {th }}$ session, Logan's RISD schedule in the alternative stimulus $\left(\mathrm{Pepsi}^{\circledR}\right)$ condition was faded to an FT 20-s schedule (see Table 3). From that point onward, responding in this condition remained variable although rates were somewhat lower overall than those observed in the attention condition. On three separate occasions in the attention condition, rates of responding met criteria for fading; however, responding increased above criterion in the next session. After three failed attempts to fade the schedule, extinction was implemented in the attention condition. The schedule in the Pepsi ${ }^{\circledR}$ condition, however, was successfully faded to an FT 1-min schedule in this initial component (i.e., until extinction was implemented in the attention condition).

Manding occurred at relatively stable rates in both conditions of the first treatment phase (RISD without extinction). Manding was higher in the Pepsi ${ }^{\circledR}(M=1.41)$ than in the attention ( $M=0.64)$ condition. One interpretation of this finding is that, in the Pepsi ${ }^{\circledR}$ condition, attention was delivered only following manding whereas in the attention condition, attention delivery occurred frequently whether manding occurred or not.

RISD, without extinction (Pepsi ${ }^{\circledR}$ condition) and with extinction (attention condition), with differential reinforcement of manding

After implementation of extinction in the attention condition, rates of problem behavior quickly declined to well below the criterion for fading $(M=1.01)$. Rates of problem behavior increased markedly, however, in the Pepsi ${ }^{\circledR}$ conditions $(M=32.39)$, suggesting a possible positive behavioral contrast effect (see Williams, 1983 for a review). In an unsuccessful attempt to eliminate this contrast effect, sessions were conducted in blocks of three. Nevertheless, rates of problem behavior in the FT Pepsi ${ }^{\circledR}$ condition remained high and extinction was implemented in this condition.

When extinction was implemented in the attention condition, manding increased somewhat $(M=1.55)$, although rates were variable (range=0.1 to 4.9). Manding decreased somewhat, however, in the Pepsi ${ }^{\circledR}$ condition $(M=0.34)$. This decrease may have occurred 
because, as Logan was emitting more problem behavior in this condition, attention delivery frequently occurred (contingent on problem behavior) regardless of the occurrence of manding. RISD, with extinction, with differential reinforcement of manding

When extinction was in effect in both conditions, rates of problem behavior remained low in the attention condition $(M=1.17)$ and were suppressed rapidly in the Pepsi ${ }^{\circledR}$ condition $(M=0.59)$. (One session in the attention condition was at 5.4 responses per min, which may have led to an inflated mean.)

Manding continued to occur at relatively high rates when problem behavior was placed on extinction in both conditions. Prior to the last four sessions in each condition, rates of manding occurred at similar rates in both conditions. Towards the end of the experiment, rates of manding decreased substantially in the Pepsi ${ }^{\circledR}$ condition.

\section{Nicholas}

\section{Functional analysis}

Results of the analog functional analysis conducted with Nicholas are depicted in Figure 4. Nicholas emitted the highest rates of problem behavior in the attention condition, suggesting that his problem behavior was sensitive to social attention.

Preference assessment

Due to ongoing difficulties with feeding and swallowing as well as medical concerns, Nicholas's mother identified only three soft foods for the preference assessment: oatmeal, pudding, and applesauce. In the preference assessment, Nicholas exclusively chose oatmeal when it was offered. Thus, oatmeal was tested in the next phase. 


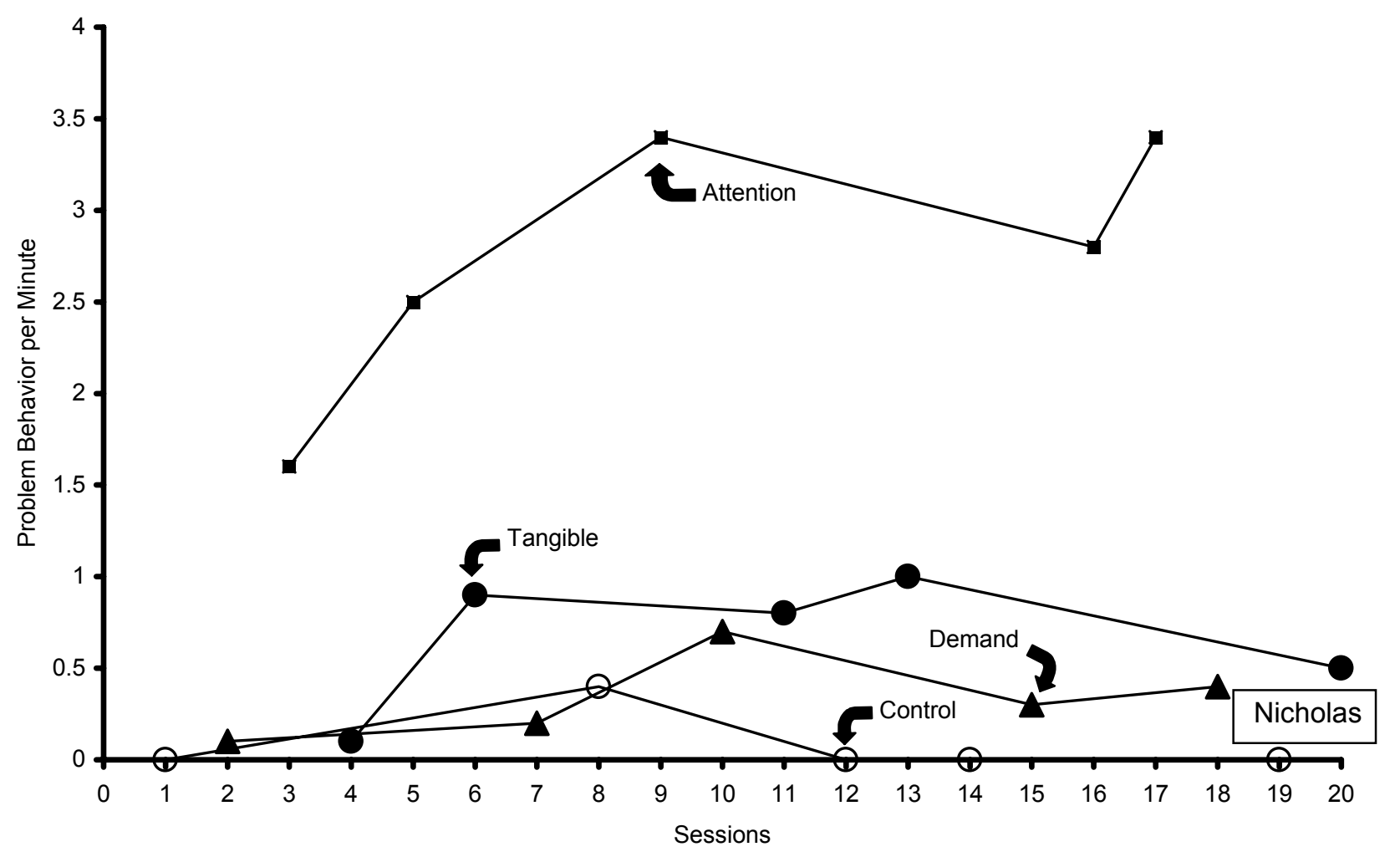

Figure 4. Rates of problem behavior during functional analysis for Nicholas.

\section{Testing the alternative stimulus}

Results of alternative stimulus testing for Nicholas are depicted in Figure 5. Rates of problem behavior in baseline (i.e., extinction of problem behavior) ranged from 0.6 to 7.2 responses per $\min (M=4.45)$. In baseline of this condition, Nicholas emitted head banging, a response not observed in the analog functional analysis, although he reportedly often engaged in head banging at home. Nicholas's parents requested that head banging be physically blocked, and this attention may have reinforced problem behavior. Regardless, the baseline condition was terminated prematurely due to head banging. Rates of problem behavior decreased when oatmeal was delivered response dependently $(M=1.1)$, although response blocking continued to occur. Results thus suggest that Nicholas's problem behavior was not maintained by oatmeal, which then was used as the alternative stimulus in the remainder of the study. 


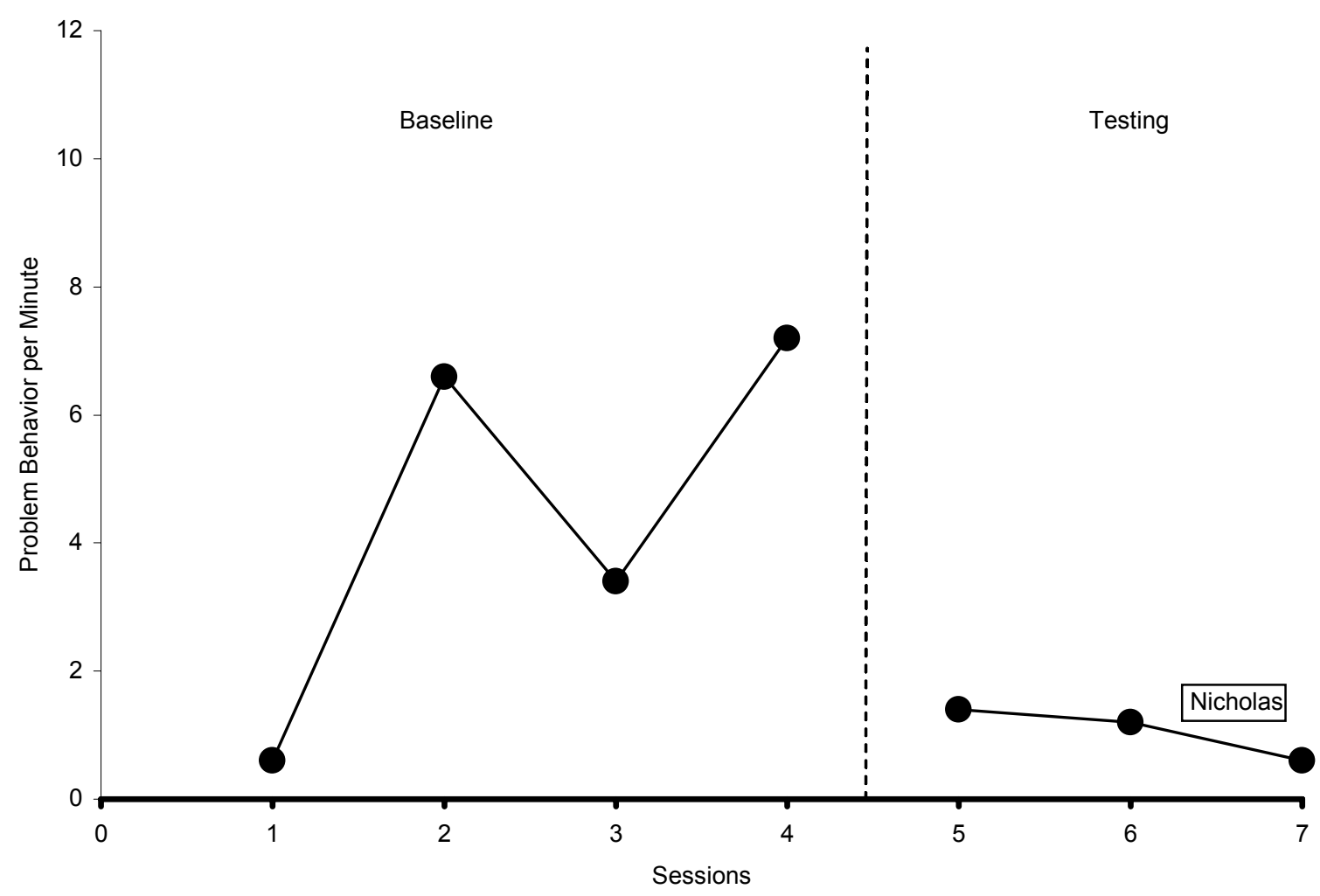

Figure 5. Rates of problem behavior during alternative-stimulus testing condition for Nicholas.

RISD, without extinction, with differential reinforcement of manding

Results obtained with Nicholas are depicted in Figure 6. Problem behavior is depicted in the top graph and manding in the bottom graph. Due to unavailability of a second trained therapist, the same therapist conducted both conditions, wearing a long, blue lab coat in the attention condition to enhance discrimination. During baseline, the mean rate of problem behavior was 6.27 responses per min. Rates of problem behavior did not differ significantly across conditions ( $M=5.80$ in the presence of the coat; $M=6.74$ in its absence). Nicholas's initial RISD schedule for both attention and oatmeal began on an FR 7.

During initial sessions of RISD without extinction, rates of problem behavior remained low in each condition, although rates consistently were lower in the oatmeal condition. In fact, in the first 11 sessions of the oatmeal condition, rates met the criteria for fading $(75 \%$ reduction 


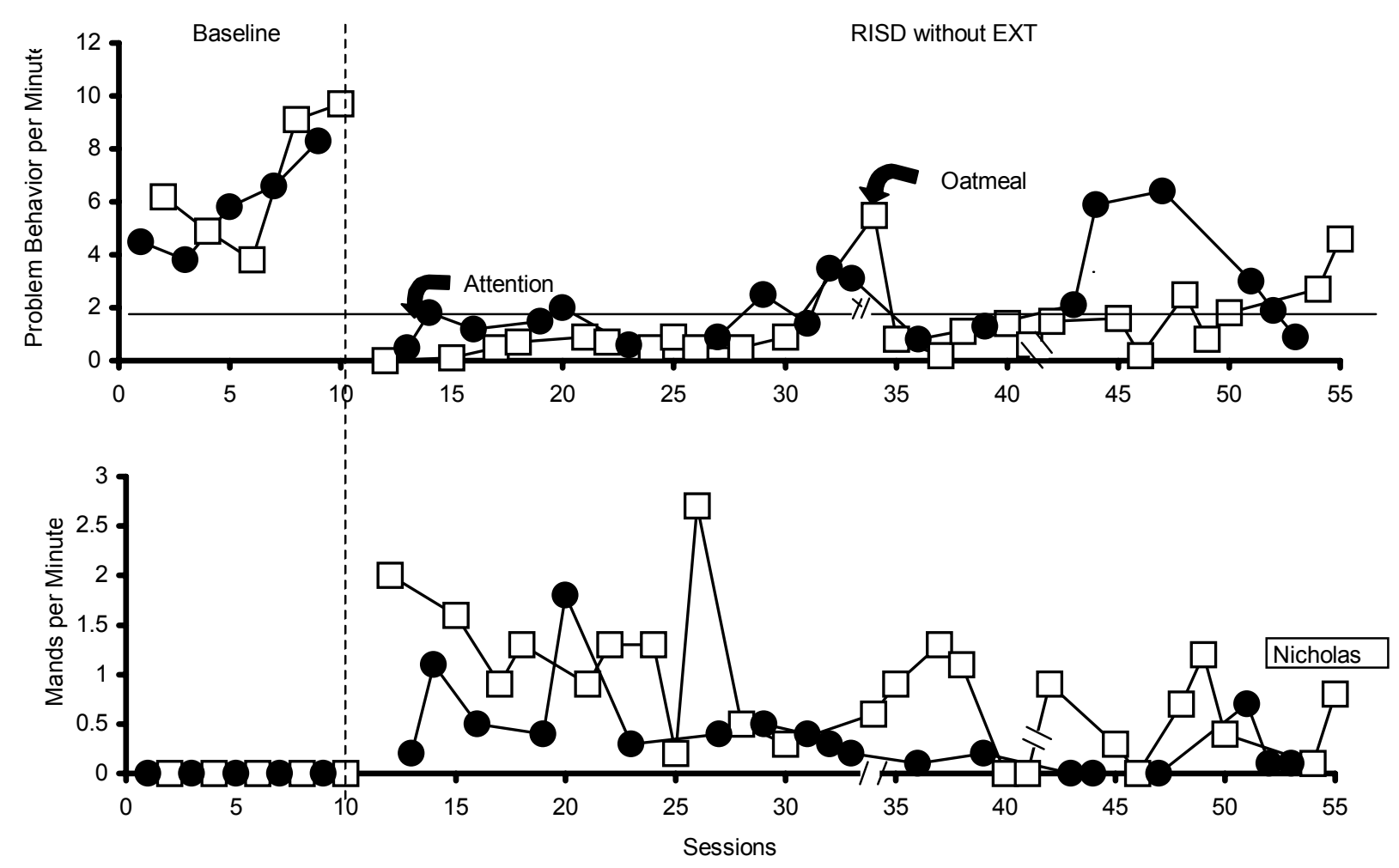

Figure 6. Rates of problem behavior and manding during evaluation of response-independent stimulus delivery for Nicholas.

relative to baseline or less than 1.57 responses per min; indicated by the horizontal line). After the $11^{\text {th }}$ session in the oatmeal condition, the RISD schedule had been faded to an FT 32-s schedule. During the first 11 sessions of FT delivery of attention, problem behavior occurred an average of 1.73 times per min. After 22 sessions had been completed (11 per condition), sessions were discontinued for approximately two weeks due to a family emergency (indicated by a break in the axis). When sessions resumed, rates of problem behavior in both conditions were higher and more variable relative to previous sessions. Following six more oatmeal sessions $(M=1.60)$ and two more attention conditions $(M=1.05)$, continuing family difficulties resulted in another two-week break, indicated by the second break in the axis. After resumption of sessions, responding increased in both conditions and it was not possible to fade the schedule of RISD to the terminal criterion of FT 1-min schedule. At this point, a meeting was held with Nicholas' parents to discuss options. His parents indicated that they would be unable to ignore Nicholas' 
self-injury at home, and thus Nicholas was withdrawn from the study. Importantly, because SIB had to be blocked, extinction would not have been implemented with integrity-blocking seemed to reinforce SIB during Phase A of testing the alternative stimulus.

Manding was highly variable throughout the experiment, but overall was higher in the oatmeal condition $(M=0.85)$ than in the attention condition $(M=0.38)$. This result is comparable to that obtained with Logan.

\section{Chapter 3 - Conclusions}

\section{General Discussion}

The combined effects of RISD and FCT on problem behavior and manding were analyzed, using both the maintaining reinforcer and an alternative stimulus. Also, the effects of extinction on RISD were studied to identify necessary components of effective RISD. Three main findings were obtained, each of which will be discussed in detail. First, with both participants, greater suppression of problem behavior was achieved in the alternative-stimulus

condition (i.e., response-independent delivery of $\mathrm{Peps}^{\circledR}{ }^{\circledR}$ or oatmeal) relative to the condition with delivery of the maintaining reinforcer (i.e., response-independent attention delivery). Second, higher rates of manding occurred with both participants in the alternative-stimulus condition relative to the maintaining-reinforcer condition. Third, RISD without extinction was not successful by previous definition for either participant.

\section{Effects of RISD Conditions on Problem Behavior}

Lower rates of problem behavior were observed consistently in the alternative stimulus condition relative to the attention condition, a finding that occurred with each subject (with Logan, prior to the implementation of extinction in the attention condition; with Nicholas, prior to the disruption of the continuity of sessions). Although previous studies (e.g., Fischer et al., 1997) have found that the implementation of RISD with an alternative stimulus resulted in nearequal suppression of problem behavior relative to a condition in which the delivery of the maintaining reinforcer was response independent, no previous studies have demonstrated relatively greater suppression under RISD with an alternative stimulus. There are at least three interpretations for this discrepant finding. 
First, time spent consuming the alternative stimulus (i.e., drinking soda, eating oatmeal) was not subtracted from total session time (cf. Fischer et al., 1997). The rationale for not subtracting this time was that consumption and target responding (i.e., problem behavior) were not mutually exclusive. In addition, in the natural environment it is desirable simply that responding decrease, even if the response-rate decrement is due to consumption time ${ }^{2}$. Anecdotally, problem behavior rarely occurred with either participant while eating or drinking. This failure to respond and consume concurrently may be responsible for the greater response suppression in the alternative stimulus condition.

A second interpretation is that the type of response-independent attention delivery was not functionally similar to the attention that maintained problem behavior. That is, although the duration and tone of attention statements were similar, the actual words differed depending on whether they were delivered dependent on problem behavior or response independently. A typical attention statement following problem behavior was, "Don't do that, you will hurt yourself." Attention following a mand or response-independent attention included statements such as, "Thanks for asking," and "You are playing very nicely." Two studies (Fisher, Ninness, Piazza, \& Owen-DeSchryver, 1996; Piazza et al., 1999) have demonstrated that the type of attention differentially affected problem behavior. The delivery of "positive" (e.g., "You're playing nicely,") or “neutral” (e.g., "It's sunny today,") versus “negative” (e.g., "Stop hitting; you're hurting me,") attention, for example, differentially affected responding. In the current study, it is possible that negative attention, rather than attention generally, maintained problem behavior. Therapists were instructed to attempt to keep constant both the tone and duration of attention delivery. The type of attention, however, necessarily differed as evident by the examples above. Thus, it is possible that the stimulus delivered in the RISD attention condition was not functionally equivalent to the reinforcer identified in the analog functional analysis ("negative" attention). If this were the case, the response-independent delivery of two different alternative stimuli, a tangible stimulus and neutral or positive attention, was compared. It is possible that, of these two alternative stimuli, the tangible (e.g., Pepsi ${ }^{\circledR}$ ) was more preferred. If neither stimulus were a maintaining reinforcer and Pepsi ${ }^{\circledR}$ were more preferred than positive attention, greater suppression in the Pepsi ${ }^{\circledR}$ condition simply may have been due to the presence of a more preferred alternative stimulus. Similar results were obtained by Fisher et al. (2000) in a 
comparison of response-independent delivery of highly-preferred and less-preferred stimuli. They found greater suppression of problem behavior when the highly-preferred stimulus was delivered response independently. This contention is supported further by the fact that both participants in the present study emitted problem behavior when neutral or positive attention was delivered either response independently or after manding. To illustrate, when positive attention delivery was continuous, Logan continued to emit problem behavior, averaging 8.73 responses per min. Therefore, perhaps the type of attention dependent on problem behavior was functionally different than that which was available response independently. Because these differences in attention delivery were not controlled, the extent to which they differentially affected responding cannot be determined. Future examination of the relation between attention type and problem behavior is necessary.

A third reason the response-independent delivery of attention may have been less effective than the response-independent delivery of an alternative stimulus is accidental reinforcement (cf. Skinner, 1948). It has been suggested elsewhere (e.g., Vollmer et al., 1997) that the accidental reinforcement of problem behavior may be a limitation of RISD. In addition, Vollmer et al. (1993) found that accidental reinforcement was more likely when problem behavior occurred at high rates in baseline. This accidental reinforcement may be due to the high likelihood of contiguity between the stimulus delivery and the target response, as contiguity is one of the most influential variables controlling the effects of reinforcement (e.g., Sizemore \& Lattal, 1977). If positive attention did reinforce problem behavior in this study (which is undetermined, as positive attention was never delivered response dependently), it is possible that the accidental reinforcement of the problem behavior occurred, as initial schedules of reinforcement were so dense.

\section{Effects of RISD Conditions on Manding}

A second finding in the current study was that attention-maintained manding occurred more often in the alternative stimulus condition relative to the attention condition for both participants. Related to this finding, Logan manded more frequently when the schedule of attention delivery was faded in both conditions. These results partly support the findings of Goh et al. (2000) showing that manding occurred reliably only when the maintaining reinforcer was delivered on a lean FT schedule. The current findings are somewhat inconsistent with those 
obtained by Goh et al. only because Logan and Nicholas reliably manded when the schedule of stimulus delivery was dense. When extinction was implemented in the attention condition for Logan, manding again increased. The findings of the present study suggest that manding is more likely to occur when the reinforcer maintaining the problem behavior is delivered on a lean schedule and extinction of the problem behavior is implemented concurrently. Returning to the possible confound of attention type, if negative attention were a more potent reinforcer than positive or neutral attention, problem behavior should occur more frequently than manding, as it resulted in negative attention. After implementation of extinction, the only type of attention available was neutral or positive attention. Manding may have increased because, although positive attention was less preferred than negative attention, it still was a reinforcer.

\section{Effects of Extinction and its Implications on a Conceptual Analysis of RISD}

Preliminarily, the present results suggest that extinction is necessary for sufficient response-rate decrements ${ }^{3}$. One should use caution in interpreting these results, however, as extinction only was implemented with one participant (i.e., Logan). Nonetheless, this result is similar to the findings of Hagopian et al. (2000; but see Lalli et al., 1997) and lends support to a matching interpretation of RISD. Hagopian et al. (2000) suggested that matching theory accurately describes the results of RISD; that is, time is allocated to the alternative stimulus being delivered which decreases problem behavior if engagement with the stimulus and problem behavior does not occur simultaneously. The finding that responding decreases at least as much (e.g., Fischer et al., 1997), if not more (e.g., the present study), with the FT delivery of an alternative stimulus relative to FT delivery of the maintaining reinforcer further supports this matching interpretation over a satiation explanation (see below).

Matching has been used both mathematically and theoretically to explain responding maintained by two schedules of response-dependent reinforcer delivery as a function of the relative rate of reinforcement arranged by each schedule (Herrnstein, 1961). Matching also can be used, however, to account for response-rate decrements with a concomitant schedule (i.e., one with both response-dependent and response-independent stimulus delivery) using the following equation:

$$
R=\left(k r_{1}\right) /\left(r_{1}+r_{2}+r_{\mathrm{o}}\right)
$$


Here, $R$ is the response rate, $r_{1}$ is the reinforcement rate correlated with that response, $r_{2}$ is the reinforcement rate provided by the response-independent delivery, $r_{\mathrm{o}}$ is the reinforcement rate provided by all other behaviors, and $K$ is a constant referring to the asymptotic rate at which $R$ can occur (Burgess \& Wearden, 1986). By appealing to this equation, the present results can be conceptualized in terms of matching. As extraneous reinforcement increases (i.e., reinforcement provided by some alternative other than the measured operant; e.g., $\left.r_{2}\right)$, responding $(R)$ decreases. Thus, as alternative sources of reinforcement are available (i.e., response-independent attention, Pepsi ${ }^{\circledR}$, oatmeal), less attention-maintained problem behavior is observed.

Another interpretation of the present results also is grounded in both basic and applied research. That is, it has been suggested that extinction is a necessary component of RISD in that disrupting the response-reinforcer dependency is critical to the success of RISD (e.g., Hagopian et al., 2000). This contention is supported in Logan's results. Specifically, response suppression to criterion was not achieved in the attention condition when the schedule of stimulus delivery decreased (i.e., where attention was delivered both response dependently and response independently), until extinction was implemented concurrently.

The finding that alternative stimulus delivery is effective also detracts from the interpretation that the effects of RISD are due to satiation. If satiation were the controlling factor, response-independent delivery of the maintaining reinforcer should result in greater decrements in responding than response-independent delivery of the alternative stimulus (during which satiation should not play a role). Satiation is not a parsimonious explanation for the effects of RISD considering recent research (e.g., Fischer et al., 1997; Hagopian et al., 2000; the present study).

This study supplements the growing body of research suggesting that extinction may be a necessary component of RISD. Thus, while some families and teachers have indicated that extinction often is difficult to implement (e.g., Miltenberger, 1997), it may be a necessary component if significant suppression is to be maintained when the RISD schedule is changed to a more realistic interval. Importantly, all studies on RISD have been conducted by trained therapists in a controlled environment. Thus, future research examining the necessity of extinction with RISD in the natural environment is necessary. 


\section{References}

Burgess, I. S., \& Wearden, J. H. (1986). Superimposition of response-independent reinforcement. Journal of the Experimental Analysis of Behavior, 45, 75-82.

Carr, E. G., \& Durand, V. M. (1985). Reducing behavior problems through functional communication training. Journal of Applied Behavior Analysis, 18, 111-126.

Cooper, J. O., Heron, T. E., \& Heward, W. L. (1987). Applied behavior analysis. Upper Saddle River, NJ: Prentice-Hall, Inc.

Durand, V. M., \& Carr, E. G. (1991). Functional communication training to reduce challenging behavior: Maintenance and application in new settings. Journal of Applied Behavior Analysis, 24, 251-264.

Durand, V. M., \& Carr, E. G. (1992). An analysis of maintenance following functional communication training. Journal of Applied Behavior Analysis, 25, 777-794.

Fischer, S. M., Iwata, B. A., \& Mazaleski, J .L. (1997). Noncontingent delivery of arbitrary reinforcers as treatment for self-injurious behavior. Journal of Applied Behavior Analysis, 30, 239-249.

Fisher, W. W., Ninness, H. A., Piazza, C. C., \& Owen-DeSchryver, J. S. (1996). On the reinforcing effects of the content of verbal attention. Journal of Applied Behavior Analysis, 29, 235-238.

Fisher, W. W., O'Connor, J. T., Kurtz, P. F., DeLeon, I. G., \& Gotjen, D. L. (2000). The effects of noncontingent delivery of high- and low-preference stimuli on attention-maintained destructive behavior. Journal of Applied Behavior Analysis, 33, 79-83.

Fisher, W. W., Piazza, C. C., Bowman, L. G., Hagopian, L. P., Owens, J. C., \& Slevin, I. (1992). A comparison of two approaches for identifying reinforcers for persons with severe and profound disabilities. Journal of Applied Behavior Analysis, 25, 491-498.

Goh, H., Iwata, B. A., \& DeLeon, I. G. (2000). Competition between noncontingent and contingent reinforcement schedules during response acquisition. Journal of Applied Behavior Analysis, 33, 195-205. 
Hagopian, L. P., Crockett, J. L., van Stone, M., DeLeon, I. G., \& Bowman, L. G. (2000). Effects of noncontingent reinforcement on problem behavior and stimulus engagement: The role of satiation, extinction, and alternative reinforcement. Journal of Applied Behavior Analysis, 33, 433-449.

Hagopian, L. P., Fisher, W. W., \& Legacy, S. M. (1994). Schedule effects of noncontingent reinforcement on attention-maintained destructive behavior in identical quadruplets. Journal of Applied Behavior Analysis, 27, 317-325.

Hagopian, L. P, Fisher, W. W., Thibault Sullivan, M., Acquisto, J., \& LeBlanc, L. A. (1998). Effectiveness of functional communication training with and without extinction and punishment: A summary of 21 inpatient cases. Journal of Applied Behavior Analysis, 31, 211-235.

Hanley, G. P., Piazza, C. C., \& Fisher, W. W. (1997). Noncontingent presentation of attention and alternative stimuli in the treatment of attention-maintained destructive behavior. Journal of Applied Behavior Analysis, 30, 229-237.

Herrnstein, R. J. (1961). Relative and absolute strength of response as a function of frequency of reinforcement. Journal of the Experimental Analysis of Behavior, 4, 267-272.

Iwata, B. A., Dorsey, M. F., Slifer, K. J., Bauman, K. E., \& Richman, G. S. (1994). Toward a functional analysis of self-injury. Journal of Applied Behavior Analysis, 27, 197-209. (Reprinted from Analysis and Intervention in Developmental Disabilities, 2, 3-20, 1982).

Kahng, S., Iwata, B. A., DeLeon, I. G., \& Wallace, M. D. (2000). A comparison of procedures for programming noncontingent reinforcement schedules. Journal of Applied Behavior Analysis, 33, 223-231.

Lalli, J. S., Casey, S. D., \& Kates, K. (1995). Reducing escape behavior and increasing task completion with functional communication training, extinction, and response chaining. Journal of Applied Behavior Analysis, 28, 261-268.

Lalli, J. S., Casey, S. D., \& Kates, K. (1997). Noncontingent reinforcement as treatment for severe problem behavior: Some procedural variations. Journal of Applied Behavior Analysis, 30, 127-137. 
Lattal, K. A. (1972). Response-reinforcer independence and conventional extinction after fixedinterval and variable-interval schedules. Journal of the Experimental Analysis of Behavior, 18, 133-140.

Lerman, D. C., \& Iwata, B. A. (1993). Descriptive and experimental analyses of variables maintaining self-injurious behavior. Journal of Applied Behavior Analysis, 26, 293-319.

Mace, F. C., \& Lalli, J. S. (1991). Linking descriptive and experimental analyses in the treatment of bizarre speech. Journal of Applied Behavior Analysis, 24, 553-562.

Marcus, B. A., \& Vollmer, T. R. (1996). Combining noncontingent reinforcement and differential reinforcement schedules as treatment for aberrant behavior. Journal of Applied Behavior Analysis, 29, 43-51.

Michael, J. (1982). Distinguishing between discriminative and motivational functions of stimuli. Journal of the Experimental Analysis of Behavior, 37, 149-155.

Miltenberger, R. G. (1997). Behavior modification: Principles and procedures. Pacific Grove, CA: Brooks/Cole Publishing Company.

Pelios, L., Morren, J., Tesch, D., \& Axlerod, S. (1999). The impact of functional analysis methodology on treatment choice for self-injurious and aggressive behavior. Journal of Applied Behavior Analysis, 32, 185-195.

Piazza, C. C., Bowman, L. G., Contrucci, S. A., Delia, M. D., Adelinis, J. D., \& Goh, H. (1999). An evaluation of the properties of attention as reinforcement for destructive and appropriate behavior. Journal of Applied Behavior Analysis, 32, 437-449.

Poling, A., \& Normand, M. (1999). Noncontingent reinforcement: An inappropriate description of time-based schedules that reduce behavior. Journal of Applied Behavior Analysis, 32, 237-238.

Roscoe, E. M., Iwata, B. A., \& Goh, H. (1998) A comparison of noncontingent reinforcement and sensory extinction as treatments for self-injurious behavior. Journal of Applied Behavior Analysis, 31, 635-646.

Shirley, M. J., Iwata, B. A., \& Kahng, S. (1999). False-positive maintenance of self-injurious behavior by access to tangible reinforcement. Journal of Applied Behavior Analysis, 32, 201-204. 
Shukla, S., \& Albin, R. W. (1996). Effects of extinction alone and extinction plus functional communication training on covariation of problem behaviors. Journal of Applied Behavior Analysis, 29, 565-568.

Sizemore, O. J., \& Lattal, K. A. (1977). Dependency, temporal contiguity, and responseindependent reinforcement. Journal of the Experimental Analysis of Behavior, 27, 119-125.

Skinner, B. F. (1948). "Superstition" in the pigeon. Journal of Experimental Psychology, 38, $168-272$.

Tucker, M., Sigafoos, J., \& Bushell, H. (1998). Use of noncontingent reinforcement in the treatment of challenging behavior. Behavior Modification, 22, 529-547.

Vollmer, T. R. (1999). Noncontingent reinforcement: Some additional comments. Journal of Applied Behavior Analysis, 32, 239-240.

Vollmer, T. R., Iwata, B. A., Zarcone, J. R., Smith, R. G., \& Mazaleski, J. L. (1993). The role of attention in the treatment of attention-maintained self-injurious behavior: Noncontingent reinforcement and differential reinforcement of other behavior. Journal of Applied Behavior Analysis, 26, 9-21.

Vollmer, T.R., Marcus, B.A., Ringdahl, J.E. (1995). Noncontingent escape as treatment for self-injurious behavior maintained by negative reinforcement. Journal of Applied Behavior Analysis, 28, 15-26.

Vollmer, T.R., Ringdahl, J.E., Roane, H.S., Marcus, B.A. (1997). Negative side effects of noncontingent reinforcement. Journal of Applied Behavior Analysis, 30, 161164.

Wacker, D.P., Steege, M.W., Northup, J., Sasso, G., Berg, W., Reimers, T., Cooper, L., Cigrand, K., Donn, L. (1990). A component analysis of functional communication training across three topographies of severe behavior problems. Journal of Applied Behavior Analysis, 23, 417-429.

Williams, B. A. (1983). Another look at contrast in multiple schedules. Journal of the Experimental Analysis of Behavior, 39, 345-384. 
Zeiler, M. D. (1968). Fixed and variable schedules of response-independent reinforcement. Journal of the Experimental Analysis of Behavior, 11, 405-414. 


\section{Footnotes}

${ }^{1}$ Where means are given, they represent means of every session of the referent condition in that phase.

${ }^{2}$ If the alternative stimulus were a toy, for example, instead of food, it would be appropriate for the participant to interact with the toy instead of engaging in problem behavior.

${ }^{3}$ A response-rate reduction was achieved in both conditions of RISD; however, reductions did not meet criteria set for "successful" terminal rates (i.e., $80 \%$ reduction from baseline for Logan and $75 \%$ reduction from baseline for Nicholas) and stabilize there. 